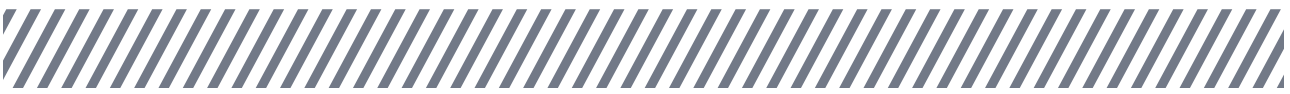

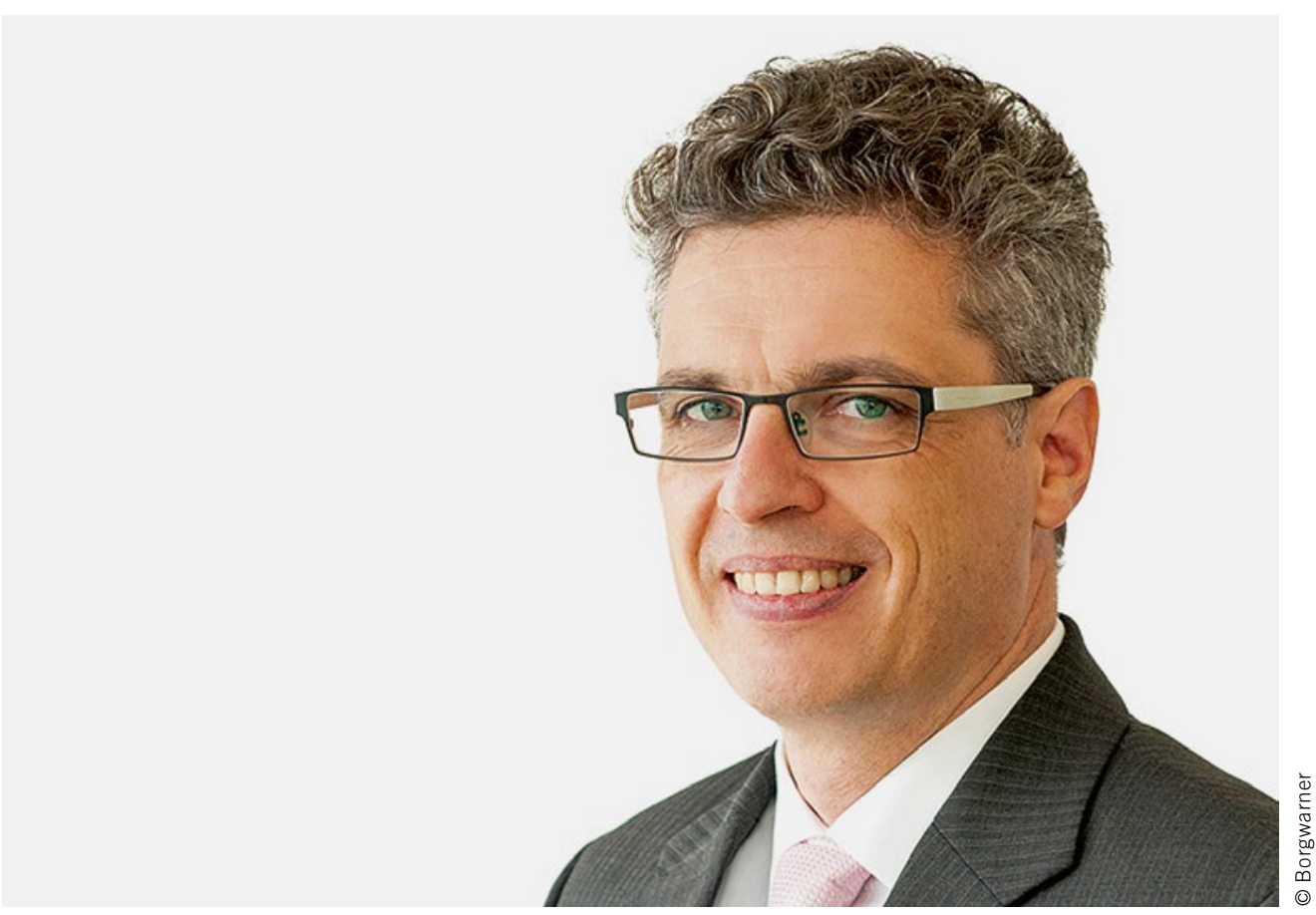

Eckart Gold,

Director Engineering, Borgwarner Transmission Systems, Shanghai, China

\section{P2-Architekturen sind zukunftsfähig}

Zunehmendes Umweltbewusstsein und konsequenter Klimaschutz führen weltweit zu neuen Umweltrichtlinien und strengeren Abgasnormen. Dies stellt Automobilhersteller vor wachsende Herausforderungen und erhöht den Kostendruck: Sie müssen die Energieeffizienz ihrer Fahrzeuge steigern und die Schadstoffemissionen verringern. Sowohl Hersteller als auch Zulieferer befassen sich daher intensiv mit Konzepten für Hybrid- und Elektrofahrzeuge. Im Jahr 2019 belief sich der Bestand an Pkw mit Hybridantrieb auf rund 341.000 Einheiten in Deutschland. 2006 waren noch etwa 6000 Hybridfahrzeuge in Deutschland zugelassen.

Für die Hybridisierung vom Mild- über Plug-in- bis zu Vollhybriden stehen unterschiedliche Technologien und Antriebsstrangarchitekturen wie P0, P1, P2, P3, P4 und PS (Powersplit) zur Verfügung. Im Fokus stehen P1- und P2-Konfigurationen, die den Elektromotor zwischen Verbrennungsmotor und Getriebe platzieren. Ich bin der Überzeugung, dass insbesondere die P2-Konfiguration eine wichtige Rolle in zukünftigen Hybridarchitekturen einnehmen wird, da diese im Gegensatz zu P1 eine Trennkupplung zur Entkopplung des Verbrennungsmotors nutzt und damit rein elektrisches Fahren ermöglicht.

Innerhalb der P2-Hybridarchitektur sind verschiedene Konfigurationen zur Positionierung des Elektromotors möglich. Eine koaxiale Anordnung eignet sich gut für Antriebsstränge mit Längsmotor, die mehr Platz für die Integration des Elektromotors bieten. Beim gleichzeitigen Einsatz eines Doppel- kupplungsgetriebes lassen sich Trennkupplung und Doppelkupplungsmodul innerhalb des Elektromotors integrieren. Achsparallele Konfigurationen werden oft in Anwendungen mit quer eingebautem Motor realisiert.

Innovative Technologien wie P2-Hybridmodule eignen sich generell für verschiedene Getriebearten einschließlich Schaltgetriebe. Sie können eine einfache Trennkupplung enthalten oder eine nasslaufende Reibkupplung für maximale Funktionalität und Langlebigkeit bei kompakten Maßen. Koaxiale P2-Module, bei denen der E-Motor direkt auf der Hauptachse sitzt, sind eine kompakte Variante, die mit geringem weiteren Platzbedarf in bestehende Antriebsstränge integriert werden können. Dass eine P2-Konfiguration eine der zukunftsfähigsten Architekturen zur Hybridisierung darstellt, zeigt sich für mich auch daran, dass diese flexibel auf Kundenspezifikationen abstimmbar ist und Hybridfunktionen wie Stopp-Start, regeneratives Bremsen, elektrische Motoraufladung sowie rein elektrisches Fahren ermöglicht. Mit überschaubaren Zusatzinvestitionen können so bereits existierende Basisgetriebe überzeugend hybridisiert werden.

Ich bin fest davon überzeugt, dass die P2-Architektur einen wichtigen Beitrag zum Erfolg von hybridisierten Fahrzeugen leisten wird, da sie Effizienz, Flexibilität in den Anwendungsmöglichkeiten und Langlebigkeit, insbesondere bei Integration von naßlaufenden Trennkupplungen, vereint. 